\title{
Hayatullah AHMADZAI* \\ How is Off-farm Income Linked to On-farm Diversification? Evidence from Afghanistan
}

\begin{abstract}
The analysis in this paper estimates micro-economic drivers of diversity in crop production in Afghanistan with particular emphasis on the implications of household access to non-farm income. Descriptive analysis shows that a third of farmers do not diversify, while the majority of those that do, grow only two or three crops. Econometric analysis reveals that while landholding size, farm characteristics and assets, and proximity to markets significantly increase diversification, a significantly lower degree of diversification is found for households with higher non-farm income. This is consistent with the hypothesis that allocation of farm labour away from non-farm activities decreases diversity due to negative labour effects, perhaps because the opportunity cost of farm labour is higher than rural wages. Identification through instrumental variables confirms endogeneity in off-farm income, revealing that unobserved factors such as risk-aversion behaviour and relative efficiency may drive household decisions to diversify into both non-farm activity and crop mixing.
\end{abstract}

Keywords: Off-farm Income, Diversification, Crop Production, Cragg's Type Double Hurdle Models, Afghanistan JEL classifications: Q12, Q18

* External Research Fellow, Centre for Research in Economic Development and International Trade (CREDIT), School of Economics, University of Nottingham, Nottingham, UK NG7 2RD. E-mail: hayatullah.ahmadzai1@nottingham.ac.uk

Received: 2 February 2020, Revised: 13 March 2020, Accepted: 15 March 2020.

\section{Introduction}

In the farming business it is crucial to understand the decision-making environment and behaviour of farm households, particularly subsistence smallholders that are often exposed to various types of risk and uncertainties. Understanding decisions such as the allocation of limited resources among a diverse production portfolio requires empirical evidence. Traditionally, Crop Diversification (CD) is regarded as a management strategy, particularly in the context of subsistence farming, where farmers choose the appropriate crop mix to reduce production risks and sustain their livelihoods and income. Previous studies have established the economic value of $\mathrm{CD}$ as an alternative strategy that farmers utilise to enhance productivity and even improve and sustain their incomes (Joshi et al., 2007; Kurosaki, 2003; Weinberger and Lumpkin, 2007). To respond effectively to changing market demand and altering consumption patterns, both farmers and agriculture policy makers require a solid empirical understanding of the production decision-making environment, farmers' socio-economic characteristics and the behaviours that drive decisions regarding crop diversification. This paper aims to explore farm households' decisions with regard to the magnitude of crop diversification at the farm level in Afghanistan. It analyses the extent of diversity in crop production, and the empirical relationship between $\mathrm{CD}$ and household socio-economic, demographic, farm, and farmer characteristics with a key focus on household off-farm income.

Heterogeneity in farmer crop portfolios under a given set of socio-economic circumstances is an important empirical discussion. Even in the presence of high-return alternatives both on- and off-farm, a large number of farm households still engage in producing low yield food commodities (mainly staple food grains), and crop portfolio choices vary greatly among similar households (Stoeffler, 2016). Hence, farmer's knowledge, technical know-how, and production management practices have critical implications for their income and costs. This implies that without additional costs, there is a great potential for farm households to improve their productivity and income simply by adding high value crops to their production agenda. In addition, markets for particular commodities are imperfect and often fail to facilitate the efficient trade of farm produce, forcing farmers to adjust their production decisions to compensate for losses due to the presence of such market risks. These decisions often involve opting for crop or enterprise diversification to a lesser or greater extent.

Since emerging out of conflict and the establishment of a market-led economy in 2001, Afghanistan's agricultural economy has undergone a drastic policy change, which has created opportunities but also posed risks and uncertainties. The primary emphasis of Afghanistan's National Development Framework (ANDF) 2009 is to increase productivity so as to attain food self-sufficiency and increase farm incomes at national, regional, and household levels. With increased international aid being pledged, Afghanistan's economy grew at a steady rate of 9.4\% during 2003-2012 with a significant contribution (about 25\%) coming from the agriculture sector (World Bank, 2014). Economic growth has been accompanied by changes in agriculture production and consumption patterns, whilst other economic sectors (e.g. services and manufacturing industries) have been revitalised. With the revitalisation of other sectors and improved levels of education, farm households may have had the opportunity to diversify into off-farm activities. This highlights the importance of understanding the household decisions about labour and resource allocation between on- and off-farm activities.

Current studies on production efficiency find evidence of a positive relationship between crop diversification and production efficiency in Afghanistan (Ahmadzai, 2017; Tavva et al., 2017). Broader research also confirms that CD significantly improves farm level efficiency in other countries with 
a similar socioeconomic context (Coelli and Fleming, 2004; Ogundari, 2013; Rahman, 2009). However, Afghanistan's agriculture sector is still highly dominated by production of staple food grains (mainly wheat), leaving production systems highly undiversified. In addition, the decrease in farm income among rice/wheat producers in Afghanistan due to declining productivity has triggered a change toward farm diversification, especially a shift in production from staple food crops to higher value commodities (Oushy, 2010). Empirical evidence suggests that grain-based production systems may not continue to contribute as significantly in countries with a policy focus on raising incomes and production of high value market crops, generating employment opportunities, and alleviating poverty (Joshi et al., 2007). This therefore calls for a transformation in agriculture systems to diversify towards high value crops such as vegetables and fruits.

\section{Concept and Measures of Crop Diversification}

There are two common and complementary approaches to crop diversification in agriculture, namely horizontal and vertical diversification. Horizontal diversification as a primary approach to crop diversification, takes place through crop intensification by adding new crops to existing production line or cropping systems. Vertical diversification involves value-added activities such as processing, branding, packaging, and other post-harvest activities to enhance the marketability of farm product. In the context of this study, diversification is defined as a shift in production portfolio away from mono-cropping to adopting a multiple cropping system.

The most common method to measure the extent of crop diversification is the calculation of a vector of income/revenue shares related to different income sources. While this approach puts diversification and income changes directly into the relationship, a relevant part of information related to different aspects of diversification is neglected such as the actual number of crops grown (Asfaw et al., 2018; Barrett and Reardon, 2000). The diversity methods that measure crop or species richness are usually used in the ecological research to capture spatial biodiversity of crops and the richness of genetic resources. Count measures provide a general level of overall diversity on a farm, but do not account for whether the farm is growing high value cash crops or staple crops and the percentage of resources allocated among different crops (Turner, 2014).

Given the objective of this study, Composite Entropy Index (CEI) was selected as a primary measure for crop diversification. In addition to revenue shares of individual crops, CEI gives due weighting to the total number of crops grown by the farm household. This is important as the revenue share captures the relative importance of crops based on their economic value which may largely vary depending on the type of crops (i.e. the value of the index will be higher for households that grow high value crops). Thus, the CEI index is sensitive to the changes in the number of crops and their respective revenues. While the CEI index possesses all the desirable properties of Entropy and Modified Entropy Indices, it is adjusted by the number of crops. The CEI can be calculated as:

$$
\begin{aligned}
& D_{i}=-\left[\sum_{n=1}^{N} P_{n} \log _{N} P_{n}\right]\left[1-\frac{1}{N}\right]= \\
& =\sum_{n=1}^{N} \frac{\ln P_{n}}{\ln N}\left[P_{n}-\frac{P_{n}}{N}\right]
\end{aligned}
$$

Where $D_{i}$ represents CEI, $P_{n}$ is the share of revenue from the $n^{\text {th }}$ crop (for $n=1,2, \ldots, N$ ) grown by the $i^{\text {th }}$ farmer, and is the number of total crops grown in a given year. The computed value of the index increases with level of diversification ranging from 0 implying no diversification (i.e. monocropping) to 1 implying the highest level of CD.

\section{Theoretical Framework and the Agriculture Household Model}

Farm household decisions pertaining to crop choices and the extent of diversification can be best understood in the context of the standard farm household model initially developed by Singh et al. (1986) which assumes farm households are both consumers and producers of agricultural goods operating under a number of constraints. Previous studies adopted this approach to explore the decision of farm households with regard to the intensity of farm or crop diversification (Hitayezu et al., 2016; Cavatassi et al., 2012; Benin et al., 2004; Van Dusen and Taylor, 2005).

Proceeding according to the household model, we may consider an agricultural household that maximises utility over a set of consumption goods produced on the farm $\left(C_{f}\right)$, a set of purchased non-farm commodities $\left(X_{n f}\right)$, and leisure $(l)$. The expected utility gained from various combinations and levels of consumption goods directly depends on the vector of preferences of the household, denoted by $\Phi^{h h}$, shaped by household socio-economic, cultural, and other exogenous factors. This maximisation problem can be written as:

$$
\max _{C_{f}, C_{n f}, L, X, A} U\left(C_{f}, C_{n f}, l \mid \Phi^{h h}\right)
$$

Subject to the constraints facing the household:

$$
\begin{aligned}
& p_{f}\left(Q_{f}-C_{f}\right)-C\left(Q_{f} \mid \Phi^{f}\right)+Y_{n f}= \\
& =p_{n f} C_{n f}+w\left(L_{f}+L_{n f}\right), \\
& Q_{f}=f\left(\alpha, L, X_{f} \mid A, \Phi^{f}\right), \\
& T=\left(L_{f}+L_{n f}\right), \\
& Y_{n f}=y\left(L_{n f} \mid \Phi^{n f}\right),
\end{aligned}
$$

The utility is constrained by the general budget constraint (Equation 3) such that the maximum expenditures of time 
$w\left(L_{f}+L_{n f}\right)$ and money $p_{n f}+C_{n f}$ cannot exceed the total income of a farm household in a given decision-making period. Total household income is composed of farm income $p_{f}\left(Q_{f}-C_{f}\right)$ net of production costs $C\left(Q_{f} \mid \Phi^{f}\right)$, and off-farm income denoted by $Y_{n f}$ that includes remittances, stocks carried over, and other transfers which are exogenous to the crop choices. The amount of agriculture produce consumed by the household $\left(C_{f}\right)$ or sold $Q_{f}-C_{f}$ are chosen from the crop(s) output $Q_{f}$ (for crop $j=1,2,3, \ldots J$ that household chooses) which is constrained by the production technology embedded here in the cost function $C\left(Q_{f} \mid \Phi^{f}\right)$ where $\Phi^{f}$ is a vector collecting exogenous farm characteristics. Household decisions about the number of crops and the quantity is constrained by the fixed technology constraint (Equation 4) such that the quantity of goods produced on the farm $Q_{f}$ is a function of purchased inputs $\left(X_{f}\right)$, Labour $\left(L^{f}\right)$, a given area of land $(A)$ which is allocated to different crops (here denoted by $\alpha$ or the set of share of land allocated between $J$ crops such that $\sum_{j=1}^{J} \alpha=1$, and exogenous characteristics of the farm $\Phi^{f}$. According to Benin et al. (2004), each set of area shares implies a level or combination of crop outputs, hence the objective function in Equation (1) can be re-expressed as:

$$
\max _{h} V\left(C_{f}, C_{n f}, l \mid \Phi^{h h}\right),
$$

Where $h=\left(\left(\alpha_{1}, \alpha_{2}, \alpha_{3}, \ldots \alpha_{n}\right) \geq 0, C_{f}, C_{n f}, X\right.$, and $\left.\left.L\right)\right)$. The allocation of labour is constrained by the household total labour time (Equation 4) which is denoted by $(T)$ available for off-and on-farm activities (denoted by $L^{f}$ and $L^{n f}$ ) and leisure $(l)$.

Assuming that households maximise utility and markets for farm goods function perfectly, then production decisions by farm households can be made separately from the consumption decisions. Thus, the level of crop diversification is driven by net returns which are determined by market wage, input and output prices $\left(w, p_{x}\right.$, and $\left.p_{f}\right)$, and farm physical characteristics $\left(\Phi^{f}\right)$. However, production and consumption decisions cannot be separated under imperfect market conditions, then the household optimal choice $h^{*}=\left(\alpha^{*}, L^{*}, C_{f}^{*}, C_{n f}^{*}, X^{*}\right)$ can be expressed as a reduced form function of land holding size, income, and household, farm, and market characteristics. It therefore follows that:

$$
h^{*}=h^{*}\left[\alpha^{*}\left(A, Y_{n f}, \Phi^{h h}, \Phi^{f}, \Phi^{m}\right)\right],
$$

Assuming that households do not explicitly value crop diversification (i.e. it is not reflected explicitly in the utility function itself) and that it is the outcome of choices made in a constrained optimisation problem rather than an explicit choice (Benin et al., 2004; Van Dusen and Taylor, 2005), then crop diversification $(D)$, can be expressed as a derived demand function given by:

$$
D=D\left[\alpha^{*}\left(A, L, Y_{n f}, \Phi^{h h}, \Phi^{f}, \Phi^{n f}, \Phi^{m}\right)\right],
$$

Where $D$ represents diversification measured by composite entropy index of crop diversity at the household level. Equation (9) indicate that crop diversification is a function of the initial endowments of labour $(L)$, land $(A)$, exogenous non-farm income $\left(Y_{n f}\right)$, farm household characteristics $\left(\Phi^{h h}\right)$, farm characteristics $\left(\Phi^{f}\right)$, and market conditions $\left(\Phi^{m}\right)$.

\section{Estimation Strategy}

\section{Identification}

In the context of subsistence small-scale agricultural systems, farming often fails to provide a sufficient livelihood. Though it may remain a household's primary source of income, such households often seek alternative means of income by participating in off-farm activities. This results in the reallocation of production resources among on- and off-farm. This is consistent with the narrative that allocation of farm labour away to off-farm activities decrease diversity due to negative labour effects, particularly when the opportunity cost of household labour is higher than off-farm wages under imperfect markets implying non-separability between households' farm profits and off-farm earnings as argued by Chavas et al. (2005). Conversely, off-farm income may have a positive impact on crop diversity due to the overall income effects enabling households to purchase sufficient production inputs required for different crops.

Meanwhile, there might be a third category of unobserved factors affecting both CD as well as diversification towards off-farm activities leading to the endogeneity problem. Subsistence farmers are typically risk-averse and may tend to diversify into both crop diversification and off-farm activities. Given that earning additional off-farm income might also be used as a diversification strategy by some households to spread risk outside the farming sector, one would expect the parameter estimate of off-farm income to be biased upwards if endogeneity is not accounted for. Other examples of these unobserved factors could be the entrepreneurial ability and relative efficiency that can influence both decisions. In addition, the presence of measurement error attributed to the recall of the extent of non-farm income by the household (Zereyesus et al., 2017) may cause the coefficient of off-farm income to be biased towards zero.

The cross-section household level data used in this study do not allow to control for unobserved household fixed effects, so instrumental variable (IV) techniques are employed. Two instruments are used to control for the endogeneity bias in off-farm income. Firstly, the share of aggregate off-farm income in the total income for all households in a given district. Controlling directly for the household's family labour and regional fixed effects by including household size and agroecological dummies in the analysis, the only pathway for the instrument to influence household decisions is through the household non-farm income activities. It is important to note that data in the sample comes from 349 districts (with 50 farm households on average) and 34 provinces.

According to Diiro and Sam (2015), this instrument captures the status of local non-farm labour market; higher share of non-farm income signifies a high prevalence of nonfarm employment opportunities at a district level which, in turn, translates into greater potential for households to diver- 
sify into off-farm activities. Kilic et al. (2009) use share of non-farm employment within a district as an instrument for off-farm income, noting that, because the instrument is constructed at the district level, when regional fixed effects are controlled for it is unlikely for the instrument to have a direct effect on the farming decisions of households. Smale et al. (2016) studied the relationship between off-farm work and farm output and used share of total non-farm earnings (business and salary) in total income by location as an instrument for off-farm income. Gebregziabher et al. (2012) used unemployment rate at the district level to control for potential endogeneity in off-farm income. Similarly, in examining the relationship between participation in non-agricultural labour activities and farm production decisions, Stampini and Davis (2009) used a dummy variable for the existence of off-farm employment opportunities in the commune.

Secondly, we use district level lagged values of off-farm income from year 2011/12 to instrument for off-farm income. Data on lagged off-farm income comes from the same survey conducted by CSO previously referred to as the National Risk \& Vulnerability Assessment (NRVA). Off-farm income from the past is expected to positively affect farmer's current non-farm activities. Diiro and Sam (2015) uses off-farm income from previous years as an instrument to control for endogeneity in off-farm income suggesting that income from previous years represents an important form of financial endowment that assists farm households to invest in productive farm assets. One might argue the generation of income is a dynamic process and that transitory values of past income will influence current farming decisions. However, we use district level aggregate lagged income (not household level) as an instrument to capture the overall non-farm employment status. There is also evidence that smallholders are less likely to leave cash money on the table to transfer them from one season to another (Duflo et al., 2008).

\section{Econometric Specification}

As not every farm household will diversify or choose to diversify, a censoring issue underlies the empirical model. Although theoretically the dependent variable (CEI) is censored on both sides because it is bounded by 0 and 1 , however, there are no computed values for CEI that are 1 . Since the dependent variable is censored at 0 for $33 \%$ of the sample (i.e. non-diversifiers), conventional regression methods (i.e. OLS) fail to account for the qualitative difference between zero observations and continuous observations. Zero values of the CEI may occur for various reasons. Even though farmers may be potential diversifiers, they may not diversify due to constraints such as soil type, climate or farm size. Households may choose to remain non-diversifiers if production of certain crops offer a comparative advantage in market or production of a particular staple food crop is required for food security. In these cases, zero observations represent a corner solution which is an optimal choice by the farmers not to diversify. Therefore, the zero observations are important to be accounted for.

We employ Cragg's double hurdle model which is an alternative variant of the Tobit model to deal with the zero censorship. Cragg's double hurdle model is more flexible than the restrictive Tobit model which allows to estimate diversification as an outcome of the two-stage decision process (i.e. the first step decision to diversify is governed by a Probit model and the second step decision on the extent of diversification is modelled by a truncated regression). The endogeneity problem in the off-farm income is accounted for by employing the instrumental variables through Control Function (CF) approach. The CF approach entails that the endogenous variable is regressed over the instrumental variables (IV's) in the reduced form estimation and subsequently generalised residuals from the reduced form estimation are estimated and used as an independent variable in the structural model along with the endogenous variable (Petrin and Train, 2010; Wooldridge, 2015). Endogeneity is detected if the generalised residual is statistically significant in the structural regression. The $\mathrm{CF}$ approach is more efficient for binary outcome endogenous variables which other instrumental variable techniques (such as 2SLS, GMM, IVProbit) do not estimate efficiently. CF can also be more efficient even for weak instruments (Tadesse and Bahiigwa, 2015; Wooldridge, 2007). The reduced form is given by:

$$
I_{i}=\alpha_{i}+\gamma \pi_{i}+\beta X_{i}+\varepsilon_{i},
$$

The reduced form model is estimated by regressing the endogenous off-farm income $I_{i}$ over a number of controls $X_{i}$ and instrumental variables. Following Wooldridge (2015), the generalized residuals $\widehat{g r}$ after the reduced form regression are obtained and included in the structural model estimated by the Cragg's double hurdle model (Cragg, 1971) specified as:

$$
y_{1 i}^{*}=\alpha_{i}+\delta \widehat{g r_{i}}+\theta I_{i}+\beta X_{i}+v_{i}
$$

Decision to diversify

$$
y_{2 i}^{*}=\alpha_{i}+\widehat{\delta g r_{i}}+\theta I_{i}+\beta X_{i}+\varepsilon_{i}
$$

Extent of diversity

$$
\begin{aligned}
& y_{1}=\left\{\begin{array}{l}
1 \text { if } y_{1}^{*}>0 \\
0 \text { if } y_{1}^{*} \leq 0
\end{array}\right\} \text { and } \\
& y_{2}=\left\{\begin{array}{c}
y_{2}^{*} \text { if } y_{2}>0 \text { and } y_{1 i}^{*}>0 \\
0 \text { if otherwise }
\end{array}\right\}
\end{aligned}
$$

Where $y_{1 i}^{*}$ is the binary latent variable describing household's decision to diversify, $y_{2 i}^{*}$ is the latent variable describing household's decision on the level of diversification, and $y_{1}$ and $y_{2}$ are their observed counterparts, respectively. $\widehat{g r}$ represents the genialized residual from the reduced form question, $I_{i}$ represents the endogenous off-farm income variable, and $X_{i}$ is a vector of control variables explaining level of diversification, and $v_{i}$ and $\varepsilon_{i}$ are the error terms. 


\section{Data, Summary Statistics, and Description of Variables}

This study uses data from the Afghanistan Living Condition Survey (ALCS) conducted by the Central Statistics Organisation (CSO) in 2013/14. Geographically, the survey covered all 34 provinces of the country. In total 35 strata were identified, 34 for the provinces of Afghanistan and one for the nomadic (Kuchi) population. Households were selected on the basis of a two-stage cluster design within each stratum. In the first stage Enumeration Areas (EAs) were selected as Primary Sampling Units (PSU's) with probability proportional to Enumeration Area (EA) size. Subsequently, in the second stage ten households in each cluster were selected as the Ultimate Sampling Unit (USU). The data are representative at national and provincial level that covered about 157,262 persons within 20,786 households across the country. The survey was based on continuous data collection during a cycle of 12 months capturing important seasonal variations in a range of indicators including agriculture. Using a structured questionnaire, data were collected on a number of indictors including agriculture production, household labour, assets, education, and other household level indicators.

Initial descriptive analysis of the data showed that roughly $50 \%$ (about 9,642) households reported some engagement in agriculture. However, after accounting for missing values on key variables, the total number of usable observations reduced to 8,853 households. Furthermore, the sample of agricultural households was further investigated to examine if the household who only grow a single crop on a very small amount of land (i.e. backyard gardens) are systematically different from those who operate a relatively larger amount of land and grow major crops such as wheat, rice, cotton etc. Based on the t-test, the mean difference was found to be significant between these two categories, indicating that farmers who only produce garden crops may not be regular full-time farmers but may grow garden crops while undertaking off-farm activities as their main occupation. These farmers were therefore excluded from the sample, reducing the sample from 8,853 to 8,613 households.

Descriptive statistics show that there are a total of 22 different crops grown throughout a typical agricultural year. However, food grains such as wheat, maize, barley, and rice are the major crops. On average, wheat accounts for about $49.5 \%$ of the total value of revenue, followed by maize ( $12 \%)$, rice $(11.42 \%)$, potato $(5.5 \%)$ and onion $(5.17 \%)$. High value crops such as fruits and vegetables occupy a smaller share of the total revenues. For illustration purposes, two different measures of crop diversification CEI and Transformed Herfindahl index (THI) were constructed (Figure 1). About $33 \%$ (equivalent to 2,830 out of 8,613 ) of the households grow one crop, $48 \%$ of the farmers grow two crops, $16.5 \%$ grow three crops, and about $3.5 \%$ grow four or more, with a sample average of 1.92 crops.

Table 1 provides summary statistics for the variables used in the analysis. Average CEI and THI for the overall sample were calculated to be $29.5 \%$ and $28.3 \%$ with standard deviation of 0.23 , respectively, whereas mean CEI and THI among diversifiers are $0.44 \%$ and $42 \%$. The computed value of the CEI for $33 \%$ of the households is zero, indicating that they did not diversify (i.e. growing only one crop), whereas for $52 \%$ of farms, the value of CEI is between 0.1 and 0.50 , and for the remaining $15 \%$, CEI falls between 0.50 and 0.82 . The distribution of the THI is quite similar to that of CEI.

Descriptive statistics show that there are a total of 22 different crops grown throughout a typical agricultural year. However, food grains such as wheat, maize, barley, and rice are the major crops. On average, wheat accounts for about $49.5 \%$ of the total value of revenue, followed by maize ( $12 \%)$, rice $(11.42 \%)$, potato $(5.5 \%)$ and onion $(5.17 \%)$. High value crops such as fruits and vegetables occupy a smaller share of the total revenues. For illustration purposes, two different measures of crop diversification CEI and Transformed Herfindahl index (THI) were constructed (Figure 1). About $33 \%$ (equivalent to 2,830 out of 8,613 ) of the households grow one crop, $48 \%$ of the farmers grow two crops, $16.5 \%$ grow three crops, and about $3.5 \%$ grow four or more, with a sample average of 1.92 crops.

Table 1 provides summary statistics for the variables used in the analysis. Average CEI and THI for the overall sample were calculated to be $29.5 \%$ and $28.3 \%$ with standard deviation of 0.23 , respectively, whereas mean CEI and THI among diversifiers are $0.44 \%$ and $42 \%$. The computed value of the CEI for $33 \%$ of the households is zero, indicating that they did not diversify (i.e. growing only one crop), whereas for $52 \%$ of farms, the value of CEI is between 0.1 and 0.50 , and for the remaining $15 \%$, CEI falls between 0.50 and 0.82 . The distribution of the THI is quite similar to that of CEI.

A considerable proportion (roughly $62 \%$ ) of the sample households are engaged in off-farm activities, with a sample mean of 55K AFN of off-farm earnings per household. For households who actually have access to non-farm activities, noff-farm income is highly variable and ranges from a minimum of $10 \mathrm{~K}$ to a max of $480 \mathrm{~K}$ AFN. Some farm households clearly have significant opportunities to transfer and spread risks to off-farm activities.

Heterogeneity with respect to regional conditions may also largely affect the level of crop diversity. Rainfall throughout the year, yields, farm size, market infrastructure and conditions, and even cultural aspects may vary greatly

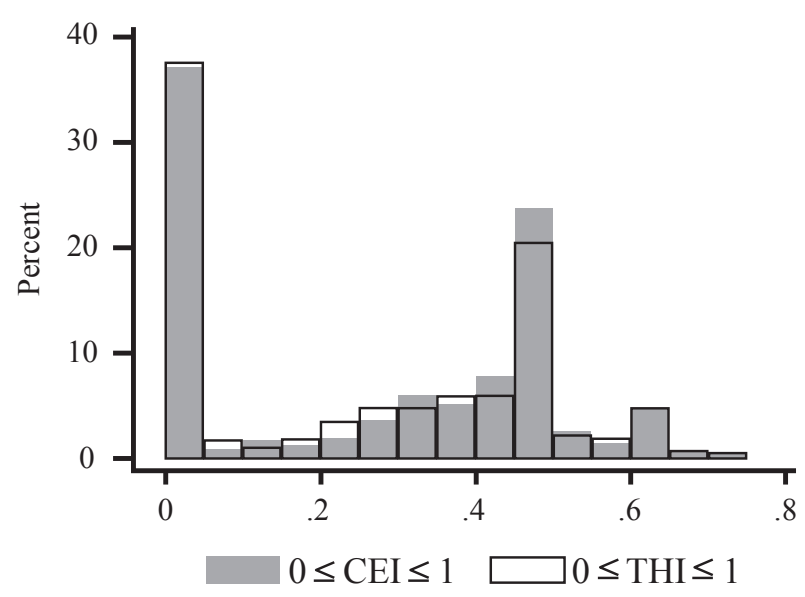

Figure 1: Distribution of Farms with respect to CEI \& THI. Source: own composition based on ALCS (2013-14) data 
Table 1: Summary statistics for variables used in the analysis.

\begin{tabular}{|c|c|c|c|c|}
\hline Variable & Mean & SD & Min & Max \\
\hline \multicolumn{5}{|l|}{ Dependent Variable } \\
\hline Composite Entropy Index $(0 \leq \mathrm{CEI} \leq 1)$ & 0.295 & 0.233 & 0.000 & 0.830 \\
\hline Transformed Herfindahl Index $(0 \leq \mathrm{THI} \leq 1)$ & 0.283 & 0.232 & 0.000 & 0.830 \\
\hline \multicolumn{5}{|l|}{ Explanatory Variables } \\
\hline Off-farm Income (in 10,000 AFN) & 5.519 & 11.05 & 0.000 & 480.0 \\
\hline Total Land (Ha) & 1.564 & 4.227 & 0.020 & 211.2 \\
\hline Transport Equipment ( $1=$ access, $0=$ otherwise $)$ & 0.450 & 0.498 & 0.000 & 1.000 \\
\hline Communication Equipment ( $1=$ access, $0=$ otherwise $)$ & 0.798 & 0.402 & 0.000 & 1.000 \\
\hline Cattle Ownership (N) & 1.477 & 1.943 & 0.000 & 31.00 \\
\hline Oxen \& Yaks $(\mathrm{N})$ & 0.248 & 0.635 & 0.000 & 9.000 \\
\hline Tractor \& Thresher $(\mathrm{N})$ & 0.052 & 0.231 & 0.000 & 4.000 \\
\hline Land Quality ( $1=$ irrigated agriculture, $0=$ irrigated $\&$ rainfed $)$ & 0.437 & 0.496 & 0.000 & 1.000 \\
\hline Landscape $(1=$ open plain, $0=$ hills $\&$ valleys $)$ & 0.753 & 0.431 & 0.000 & 1.000 \\
\hline Sufficient Irrigation Water ( $1=$ access, $0=$ otherwise $)$ & 0.448 & 0.497 & 0.000 & 1.000 \\
\hline Household Size (persons) & 8.124 & 3.474 & 1.000 & 36.00 \\
\hline Head Edu: No Formal Schooling ( $0=$ yes $)$ & 0.769 & 0.422 & 0.000 & 1.000 \\
\hline Head Edu: Primary \& Lower sec (1=yes) & 0.116 & 0.320 & 0.000 & 1.000 \\
\hline Head Edu: Upper Secondary (2=yes) & 0.079 & 0.270 & 0.000 & 1.000 \\
\hline Head Edu: Teacher College ( $3=$ yes $)$ & 0.023 & 0.150 & 0.000 & 1.000 \\
\hline Head Edu: Uni \& Postgrad (4=yes) & 0.013 & 0.115 & 0.000 & 1.000 \\
\hline Household Head Sex $(0=F, 1=M)$ & 0.995 & 0.067 & 0.000 & 1.000 \\
\hline Household Head Age (Years) & 44.11 & 13.90 & 13.000 & 98.00 \\
\hline Extension Services ( $1=$ access, $0=$ otherwise $)$ & 0.184 & 0.387 & 0.000 & 1.000 \\
\hline Distance to Nearest Road (km) & 2.513 & 8.876 & 0.000 & 100.0 \\
\hline Distance to Market $(0=$ Not reachable $)$ & 0.044 & 0.204 & 0.000 & 1.000 \\
\hline Distance to Market (1=Less than $1 \mathrm{~h})$ & 0.548 & 0.498 & 0.000 & 1.000 \\
\hline Distance to Market (2=More than $1 \mathrm{~h})$ & 0.408 & 0.492 & 0.000 & 1.000 \\
\hline AEZ 1: (1=North Eastern Mountains-NEM) & 0.023 & 0.151 & 0.000 & 1.000 \\
\hline AEZ $2(2=$ Central Mountains-CM $)$ & 0.166 & 0.372 & 0.000 & 1.000 \\
\hline AEZ 3: (1=Helmand Farah Lowlands-HFL) & 0.040 & 0.197 & 0.000 & 1.000 \\
\hline AEZ 4: (1=Southern Mountains and Foothills-SMF) & 0.198 & 0.399 & 0.000 & 1.000 \\
\hline AEZ 5: (5=Helmand Valley \& Sistan Basins-HVSB) & 0.105 & 0.306 & 0.000 & 1.000 \\
\hline AEZ 6: (6=Turkistan Plains-TP) & 0.068 & 0.252 & 0.000 & 1.000 \\
\hline AEZ 7: (7=Northern Mountains \& Foothills-NMF) & 0.183 & 0.387 & 0.000 & 1.000 \\
\hline AEZ 8: (8=Eastern Mountains \& Foothills-EMF) & 0.216 & 0.412 & 0.000 & 1.000 \\
\hline \multicolumn{5}{|l|}{ Instruments } \\
\hline IV1-Share of off-farm income in total Income within District & 0.519 & 0.294 & 0.000 & 1.000 \\
\hline IV2-Lag District Level off-farm income 2011/12 (10K AFN) & 507.6 & 568.1 & 11.975 & 9,090 \\
\hline $\mathrm{N}$ & 8,613 & & & \\
\hline
\end{tabular}

Source: own composition based on ALCS (2013-14) data

by regions that may result in different levels of the extent of crop diversification. Based on the early work by Humlum (1959) revived by Dupree (1973), Afghanistan was divided into 11 geographical zones. However, a study by Maletta and Favre (2003) concluded that not all the 11 zones have agricultural significance (i.e. some zones were classified as deserts). Based on ecological properties of land and climate, and some supplementary criteria about accessibility and prevailing agricultural activities, Maletta and Favre (2003) adopted the 8 Agro-ecological Zones (AEZ) scheme which were constructed in the form of whole districts aggregations.

\section{Empirical Results and Discussion}

Based on Equations (11) and (12), the estimated average partial effects (APE) from the Cragg's double hurdle model are reported in columns 3 and 4 of Table 2, along with the results from the reduced form model (Equation 10) in col- umn 4. For continuous variables, APE measures the change in probability of the observed, given a unit change of the independent variables, for discrete variables a change from 0 to 1 , holding all other variables constant.

It is unclear and difficult to distinguish between crop intensification or inter-cropping and crop diversification (although grains such as wheat, maize, barely, and rice occupy the absolute majority of the land which are highly unlikely to be inter-cropped). Thus, the CEI index (based on crop revenue shares and weighted by the number of crops) is likely to better fit our data as compared to the binary variable (to diversify or not), as it may fail to distinguish between intensification and diversification. However, as an additional robustness check to test the econometric specification, we ran instrumental variable Tobit (IVTobit) and instrumental variable Probit (IVProbit) models to test the possibility that the decisions to diversify and on the extent of diversification are perhaps made simultaneously. Estimated results from both models (presented in Annex 1) are qualitatively 
Table 2: Estimations of diversification decisions using Cragg's type double hurdle model.

\begin{tabular}{|c|c|c|c|c|c|c|}
\hline \multirow{3}{*}{$\begin{array}{l}\text { VARIABLES } \\
\text { Generalised residual }\end{array}$} & \multirow{2}{*}{\multicolumn{2}{|c|}{ Reduced form }} & \multirow{2}{*}{\multicolumn{2}{|c|}{$\begin{array}{c}\text { Hurdle } 1 \\
\text { Decision to diversify }\end{array}$}} & \multirow{2}{*}{\multicolumn{2}{|c|}{$\begin{array}{c}\text { Hurdle } 2 \\
\text { Extent of diversification }\end{array}$}} \\
\hline & & & & & & \\
\hline & - & - & $-0.028 * * *$ & $(0.002)$ & $-0.009 * * *$ & $(0.001)$ \\
\hline Off-farm income (10K) & - & - & $-0.002 * * *$ & $(0.000)$ & $-0.001 * * *$ & $(0.000)$ \\
\hline total land (ha) & $-0.062 * *$ & $(0.027)$ & $0.022 * * *$ & $(0.002)$ & $0.002 * * *$ & $(0.000)$ \\
\hline transport equip ( $1=$ access $)$ & $0.926^{* * *}$ & $(0.251)$ & $0.043 * * *$ & $(0.011)$ & $0.019 * * *$ & $(0.004)$ \\
\hline Communication equip ( $1=$ access $)$ & 0.394 & $(0.298)$ & $0.031 * *$ & $(0.013)$ & $0.018 * * *$ & $(0.005)$ \\
\hline Ownership of cattle (N) & $-0.144 * *$ & $(0.060)$ & $0.005^{*}$ & $(0.003)$ & $0.003 * * *$ & $(0.001)$ \\
\hline Ownership of oxen (N) & $-0.685^{* * *}$ & $(0.191)$ & $0.042 * * *$ & $(0.009)$ & $0.017 * * *$ & $(0.003)$ \\
\hline Ownership of tractor $(\mathrm{N})$ & 0.522 & $(0.503)$ & $0.132 * * *$ & $(0.027)$ & $0.030 * * *$ & $(0.008)$ \\
\hline Land quality (1=good) & -0.288 & $(0.341)$ & $0.100 * * *$ & $(0.015)$ & $0.036 * * *$ & $(0.005)$ \\
\hline Landscape ( $1=$ open plain $)$ & $0.806 * * *$ & $(0.268)$ & $0.145 * * *$ & $(0.011)$ & $0.045 * * *$ & $(0.004)$ \\
\hline Access to irrigation ( $1=$ access $)$ & $0.469 * *$ & $(0.235)$ & $0.045 * * *$ & $(0.010)$ & $0.020 * * *$ & $(0.004)$ \\
\hline HH size (persons) & $0.589 * * *$ & $(0.035)$ & $0.025 * * *$ & $(0.002)$ & $0.009 * * *$ & $(0.001)$ \\
\hline Head edu. $(1=$ primary $\&$ sec $)$ & $1.378 * * *$ & $(0.351)$ & $0.081 * * *$ & $(0.015)$ & $0.026 * * *$ & $(0.006)$ \\
\hline Head edu ( $2=$ upper sec $)$ & $3.572 * * *$ & $(0.420)$ & $0.168 * * *$ & $(0.016)$ & $0.055 * * *$ & $(0.008)$ \\
\hline Head edu. $(3=$ teacher college $)$ & $2.103 * * *$ & $(0.737)$ & $0.092 * * *$ & $(0.031)$ & $0.025 * *$ & $(0.012)$ \\
\hline Head edu. (4=uni \& grad) & $6.757 * * *$ & $(0.954)$ & $0.195 * * *$ & $(0.031)$ & $0.078 * * *$ & $(0.018)$ \\
\hline HH head sex $(1=$ male $)$ & -0.049 & $(1.620)$ & 0.104 & $(0.075)$ & $0.044 *$ & $(0.023)$ \\
\hline HH head age (years) & 0.002 & $(0.008)$ & 0.001 & $(0.000)$ & 0.000 & $(0.000)$ \\
\hline Extension service $(1=$ access $)$ & $-1.123^{* * *}$ & $(0.295)$ & -0.018 & $(0.013)$ & $-0.013 * * *$ & $(0.005)$ \\
\hline Distance to road (km) & $-0.022 *$ & $(0.013)$ & 0.000 & $(0.001)$ & $0.001 *$ & $(0.000)$ \\
\hline Distance to market $(1=<1 \mathrm{~h})$ & 0.262 & $(0.564)$ & 0.030 & $(0.025)$ & $0.020 * *$ & $(0.009)$ \\
\hline Distance to market $(2=>1 \mathrm{~h})$ & -0.448 & $(0.553)$ & 0.022 & $(0.024)$ & 0.006 & $(0.008)$ \\
\hline AEZ $1(\mathrm{CM})$ & -0.922 & $(0.769)$ & $0.124 * * *$ & $(0.036)$ & 0.013 & $(0.011)$ \\
\hline AEZ 2 (HFL) & 1.011 & $(0.929)$ & -0.033 & $(0.043)$ & $-0.028 * *$ & $(0.013)$ \\
\hline AEZ 3 (SMF) & 1.273 & $(0.787)$ & $0.304 * * *$ & $(0.036)$ & $0.068^{* * *}$ & $(0.012)$ \\
\hline AEZ 4 (HVSB) & -0.842 & $(0.881)$ & $-0.153 * * *$ & $(0.041)$ & $-0.040 * * *$ & $(0.012)$ \\
\hline AEZ 5 (TP) & -0.562 & $(0.869)$ & $-0.077 *$ & $(0.041)$ & $-0.056^{* * *}$ & $(0.012)$ \\
\hline AEZ 6 (NMF) & -0.804 & $(0.775)$ & $0.132 * * *$ & $(0.037)$ & $0.031 * * *$ & $(0.011)$ \\
\hline AEZ 7 (EMF) & -1.096 & $(0.779)$ & $0.261 * * *$ & $(0.036)$ & $0.110 * * *$ & $(0.012)$ \\
\hline IV1 & $10.612 * * *$ & $(0.485)$ & - & - & - & - \\
\hline IV2 & $0.001 * * *$ & $(0.000)$ & - & - & - & - \\
\hline Constant & $-5.833 * * *$ & 1.881 & - & - & - & - \\
\hline R-squared & 0.179 & & & & & \\
\hline Pseudo R-square & & & 0.113 & & & \\
\hline Observations & 8,613 & & 8,613 & & 8,613 & \\
\hline
\end{tabular}

Standard errors are in parenthesis. Significance is indicated by $* * * \mathrm{p}<0.01, * * \mathrm{p}<0.05,{ }^{*} \mathrm{p}<0.1$.

Source: own composition based on ALCS (2013-14) data

and quantitatively similar to those of our main results, we therefore stick to the estimations from the preferred Cragg's type hurdle model because IVTobit is restrictive (in the sense that both decisions are governed by the same process) and IVProbit fails to distinguish between crop diversification and intensification.

The reduced-form model (Equation 11) was estimated using OLS and presented as the reduced form stage estimates in Table 2. All instrumental variables had the expected significant impact on the endogenous variables. They satisfy the orthogonality conditions, implying that IVs are directly and significantly correlated with the endogenous variables but affect dependent variables in the structural models only through the inclusion of the computed generalised residuals from the reduced form. It is plausible to believe that any leftover endogeneity after using the $\mathrm{CF}$ approach will be uncorrelated with the other covariates in the structural model (Ricker-Gilbert et al., 2011).
Endogeneity in off-farm income was investigated by applying the Wald test of exogeneity. The calculated test statistic is 142.49 and rejects the null hypothesis of no endogeneity in off-farm income at $1 \%$ significance level conditional on the validity of instruments. The Amemiya-Lee-Newey overidentification test estimator was used to test the null hypothesis that the instruments are jointly valid, and that the excluded instruments are correctly excluded from the estimated equation. The result of Amemiya-Lee-Newey ${ }^{1}$ is insignificant, thus establishing the validity of the instruments. Variance Inflation Factor (VIF) was used to test for multicollinearity, the mean value of VIF was less than 10 (2.85) rejecting the possibility of potential multicollinearity in the data.

\footnotetext{
Additionally, a set of minimum distance version weak-instrument-robust tests including Anderson-Rubin (AR), Conditional Likelihood Ratio (CLR), the Lagrange Multiplier (LM), overidentification (J), and a combination of the LM and $J$ over identification (K-J) suggested by Finlay and Magnusson (2009) were also carried out. The confidence intervals for the off-farm income coefficient produced by the weak-instrument tests were not wider than the non-robust Wald confidence intervals, indicating that instruments are strong and that point estimates are robust to weak instrument bias.
} 
Estimated average partial effects illustrate negative and significant impact of household non-farm income on the decision to diversify and the extent of crop diversification. Holding other variables constant, an increase of 10,000 Afghani in off-farm income (equivalent to almost $20 \%$ of the sample mean for off-farm income) decreases the likelihood to diversify by 0.2 percent points and decreases the extent of diversification by 0.1 percent points. This is consistent with the hypothesis that allocation of farm labour away to off-farm activities decreases diversity, possibly due to negative labour effects, or perhaps because the opportunity cost of farm labour is higher than off-farm rural wages, probably due to market imperfections. Our findings of negative impact of off-farm income are consistent with the conclusions of earlier studies including Weiss and Briglauer (2000), and Mishra et al. (2004) but are in contrast with Cavatassi et al. (2012).

Holding all variables at their mean, an increase in land (i.e. total land cultivated by farm household) by one hectare increases the chances of crop diversification by 2.2 percentage points and extent of diversification by 0.2 percent points. The positive effect of land size indicates that households with a relatively larger land size have the flexibility to allocate land among a variety of crops and therefore diversify. These findings are consistent with those of Hitayezu et al. (2016) for South Africa, and McNamara and Weiss (2005) for Austria. However, Pope and Prescott (1980) found a positive and quadratic relationship between farm size and diversity arguing that there is a trade-off between scale economies and risk reduction. That is, if there are large-scale economies in an enterprise, then one might expect larger farms to be more specialised.

Farm households living in communities with better access to roads maintain higher crop diversity. Improved access implies better access to market information on demand and prices and lower transaction costs due to better market infrastructure, transport and storage facilities. Moreover, high-value horticultural crops such as vegetables and fruits are perishable and require sustained supply chain in order for the households to sell them in local markets. Rao et al. (2008) finds a significant and positive impact of road density on diversification towards high value horticultural crops in India. Turner (2014) indicated that Mozambican farmers lacking access to transport infrastructure do not allocate land to marketable cash crops. Ownership of transport equipment by the households and access to communication equipment (i.e. television, mobile phone, and radio) were also found to have a significant and positive influence on the extent of crop diversity. This further supports the argument that these communication equipment provide better access to market information and ownership of transport equipment introduces efficiency to the cost function through low-cost means of transport.

Households with greater number of livestock (cattle and oxen) maintain higher level of crop diversity. Our findings agree with Benin et al. (2004) and Cavatassi et al. (2012) that pointed out that owners of oxen tend to plant greater number of crops perhaps due the mechanical power provided by the oxen. Similarly, ownership of cattle herds increases the amount of manure produced at the farm that enhances soil fertility through adding organic materials to the soil.
Farm households that own tractors maintain higher degree of diversity enable households to utilise lands more efficiently and increases production efficiency through availability of cheaper and timely traction power.

Agricultural extension services appear to have a significant negative impact on the extent of crop diversification. This is perhaps due to the policy emphasis on achieving self-sufficiency in producing staple grain food crops. While grain, particularly wheat, is the major source of nutrition, Afghanistan still imports a substantial quantity of wheat flour so there is an aim to produce more grains domestically. Mesfin et al. (2011) arrives at a similar conclusion arguing that the negative impact of extension services is associated with the extension system favouring specialisation at macro level and overlooks the role of crop diversification in risk minimisation.

There appears to be a significant and positive relationship between land type and CD. Farmers operating on irrigated agriculture alone are significantly more diversified than their counterparts who operate a combination of irrigated and rain-fed land. In addition, farms with stable access to sufficient irrigation water (in irrigated lands) throughout the year appear to be more diversified. Afghanistan is a dry country and farmers often don't have access to sufficient irrigation water during the year. As a result, farmers are restricted to grow limited number of crops, particularly since many vegetables require greater amount of irrigation. Mesfin et al. (2011) confirms that irrigation intensity has a positive effect on crop diversity by enabling farmers to grow vegetables along other grains.

Farmers operating in the plains or on flat lands diversify more in comparison to farmers with land in valleys and hills. Altitude and slope of land effects physical conditions of farming which translates into the household decisions on the number and type of crops they choose to grow. Cavatassi et al. (2012) indicated that variability in slope of the farmland leads to greater variability in diversity. Our results are in contrast of those of Van Dusen and Taylor (2005) who found that Mexican farms located in areas with steep slope are more diversified.

We controlled for eight agroecological regions: Eastern Mountains and Foothills (EMF), Southern Mountain and Foothills (SMF), and Central Mountains (CM) were the most favourable for crop diversification compared to the reference zone (NEM). Among other heterogeneous unobserved effects such as climatic, physical conditions, and cultural conditions, the level to off-farm employment/income, access to farmland, market development infrastructure and market conditions, and road density are expected to greatly vary from region to region. Figure 2 illustrates spatial variation in crop diversification at the district level across the country.

Highly diversified areas are indicated by darker shades (CEI=0.36-0.67), and the least diversified districts with lighter shades $(\mathrm{CEI}=0-0.17)$, whereas the grey areas represent areas with no data. These areas are either areas with no agricultural significance (i.e. deserts and mountains) or could not be covered by the survey. In addition, these areas may represent the households that were surveyed but did not report any involvement in agriculture activities (i.e. households that did not report crop production). 


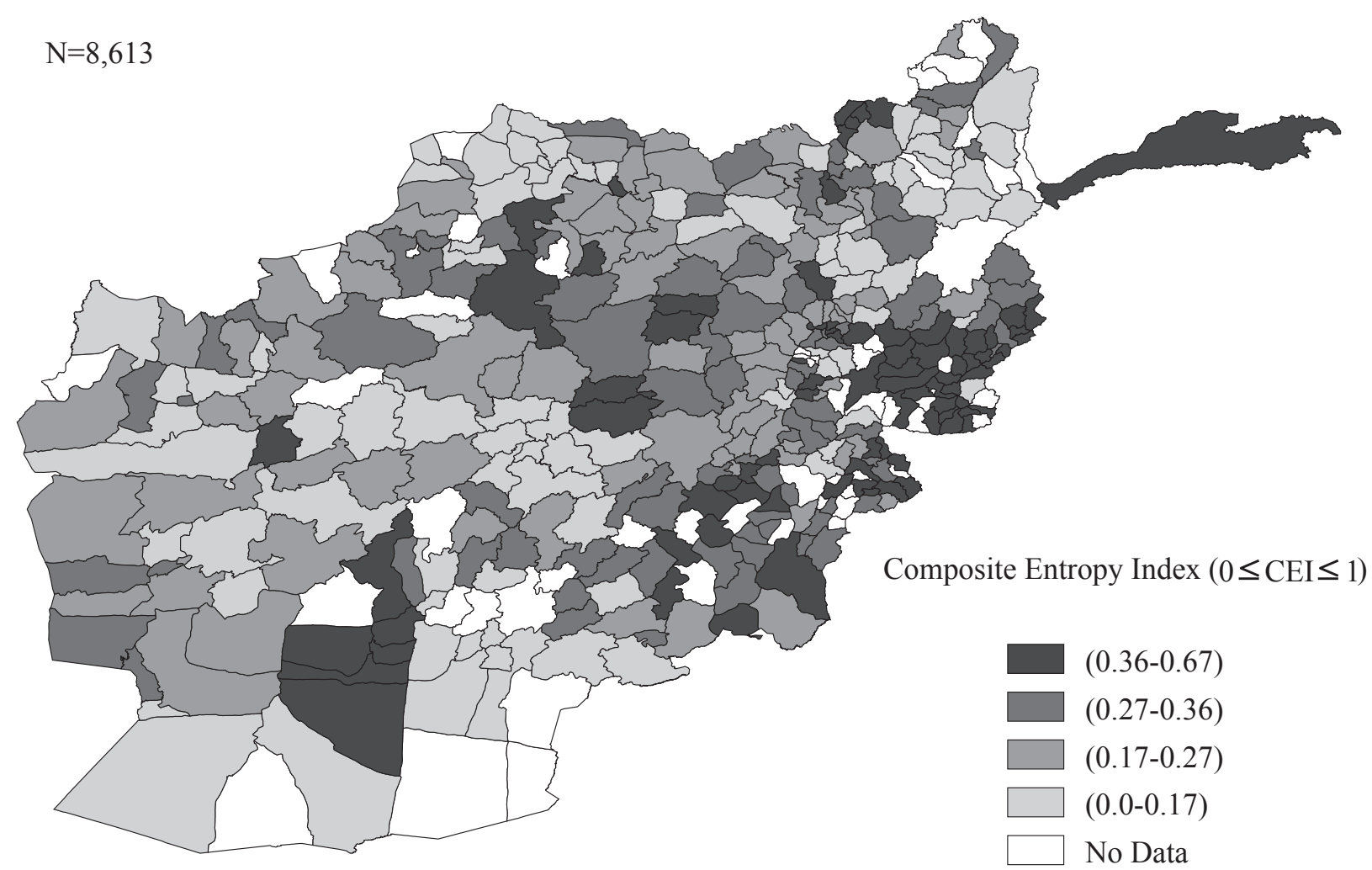

Figure 2: Map of CD at District Level.

Source: own composition based on ALCS (2013-14) data

\section{Robustness Checks}

Cultivation of opium poppy is an important aspect of farming in the context of Afghanistan that may generate systematic differences in household characteristics and their management strategies (e.g. crop diversification) across the regions, especially since opium poppy cultivation is relatively more common in some zones or provinces than others. Using information from Afghanistan's Ministry of Counter Narcotics (MCN) on major poppy producing areas, we divided our analytical sample into two sub-samples based on the intensity of poppy cultivation at the provincial level: 1) Households in main opium producing provinces were assigned in one category, and 2) Households in other provinces that were opium free according to the $\mathrm{MCN}$ report published in 2013 were assigned to another category. Subsequently, we ran our analysis for each category separately, aiming to investigate the extent to which crop diversification and other household socioeconomic characteristics can differ between opium infected and opium free areas/provinces.

Our results from the two sub-samples suggest no dramatic qualitative differences in the estimates among the two sub-groups, although there are some quantitative differences in the estimated parameters. Off-farm income is consistently significant and negatively associated with the level of crop diversification in all models. The major disparity in the estimated parameters among two groups is that crop diversification is lower in major poppy producing agroecological zones (AEZ) such as Helmand Valley and Sistan Basin (HVSB), Heart-Farah Low Lands (HFL), and Central Mountains
(CM), perhaps farm households specialize in opium production in these areas due to the extra income from poppy cultivation.

Proximity to or remoteness from urban centres is another critical aspect in the context of this study, a factor that may alter the crop diversification strategies adopted by farmers. While the narrative central to the analysis presented in this paper pursues the theory that marketisation increases crop diversification, a concern may arise that market orientation may actually motivate farmers to engage in production of specialised crops, since marketisation may offer competitive advantages for certain agricultural commodities. Conversely, subsistence farmers in remote areas may engage in crop diversification, so as to be able to meet their dietary requirement from their own production, given that their access to markets is limited. In the meantime, consistent with the narrative of marketisation-diversification assumed by this paper, if closeness to urbanisation or marketisation truly increases crop diversification, then it could be the case that farm households close to urban centres are probably diversifying way more than those located in remote areas with less access to markets, giving rise to potentially significant differences across households. In both the "marketisation-specialisation" and "marketisation-diversification" scenarios, it was important to carry out a robustness check to ensure that our main results were not driven by this spatial aspect of farming.

We therefore ran a further robustness check and split our analytical sample into two sub-groups: farm households situated within 1 our 2 hours from or to the main urban centres were assigned to one group and farms located in remote areas 
(e.g. households not located within 1 or 2 hours from the main urban centres) were assigned to another. Overall, our analysis revealed no substantial qualitative dissimilarities for the estimated coefficients across the two sub-samples. The magnitude or size of estimated coefficients varied slightly between the two sub-samples, but in general the results were similar to those of our main results. Off-farm income was consistently significant and negatively associated with the extent of crop diversification in all models. Our main results are contingent upon distance to roads, time taken to reach the market, and ownership of communication and transport equipment by the households which are sufficient to capture any variations associated with urbanisation or marketisation.

\section{Conclusions}

In this paper, we investigated the status and determinants of the extent of diversity in crop production in Afghanistan, taking a particular interest in the impact of off-farm income. The computed value of the diversity index measured by composite entropy index establishes the presence of a relatively low level of crop diversity in Afghanistan which greatly varies across the agroecological regions. With the estimated mean CEI of 0.29 (where zero is no diversification), a third of farmers do not diversify, and the majority of those that do, grow only two or three crops.

The results of the Cragg's type models revealed lower level of diversity in crop production for households with higher offfarm income. This is consistent with the hypothesis that allocation of farm labour away to non-farm activities decreases diversity due to negative labour effects, mainly because the opportunity cost of household labour is higher than off-farm wages, this possibly being the case under imperfect market conditions. Identification through instrumental variable techniques reveals an even greater impact of non-farm income on crop diversity suggesting that unobserved factors such as riskaversion behaviour or the relative efficiency of farmers may drive a household's decision towards diversification of both non-farm activities and crop diversification.

Other factors that significantly determine the intensity of crop diversity include household characteristics, farm characteristics, transaction costs (proxied for by distance to market, nearest road, ownership of transport and communication equipment), ownership of livestock units and tractors, receipt of extension services, and regional factors. Among these factors, land, household ownership of transport and communication equipment, proximity to markets, ownership of cattle, oxen, and tractors, household size and household head education appear to have a positive significant impact on crop diversity. On the contrary, the distance of farm households from roads and their degree of access to extension services were found to be negatively associated with the level of diversity in crop production. Surprisingly, low diversity was found for households with access to extension services; we infer that this might be due the emphasis of agricultural policies on the production of staple crops that are vitally important for food security.

This research is intended to contribute to the understanding of smallholder decision-making in relation to crop portfolio diversification and factors affecting it. It has particularly important implications for household's decisions about allocation of resources such as land and labour among on- and off-farm activities, especially since engagement in non-farm activities reduces crop diversity. In general, smallholder resource-poor farmers are cautiously risk-averse and try to spread risk over a diverse profile of both on-and offfam activities, particularly if the farming business experiences high volatility. Policies associated with increasing opportunities for off-farm income do not contribute to crop diversification; therefore, if crop diversification is the objective, policies must focus on farmers. Farmers that receive advice from extension agents appear to diversify less, perhaps due the emphasis of government on producing staple food crops to improve food security; thus, it is may be viable to revisit the extension services programmes to encourage crop diversification as a potential strategy for risk mitigation and income sustainability. Policies that incentivise farmers' access to regional and international markets through better forward and backward linkages can augment the diversification process. Public investment in rural infrastructure development such as roads, transportation facilities, market infrastructure, and other means to reduce transaction costs is an equally important aspect to stabilise the supply chain and thereby ensure relatively low level of crop diversity.

\section{Acknowledgement}

The author would like to thank Professor Oliver Morrissey and Professor Simon Appleton for their guidance, support, and detailed feedback. The author is also grateful to Dr. Alastair Bailey (University of Kent) and Dr. Markus Eberhardt (University of Nottingham) for their review and constructive comments on an earlier version of this paper.

\section{References}

Ahmadzai, H. (2017): Crop Diversification and Technical Efficiency in Afghanistan: Stochastic Frontier Analysis. School of Economics, University of Nottingham, CREDIT Research Paper 17/04.

Asfaw, S., Pallante, G. and Palma, A. (2018): Diversification Strategies and Adaptation Deficit: Evidence from Rural Communities in Niger. World Development, 101, 219-234. https://doi. org/10.1016/j.worlddev.2017.09.004

Barrett, C.B., Bezuneh, M., Clay, D.C. and Reardon, T. (2005): Heterogeneous Constraints, Incentives and Income Diversification Strategies in Rural Africa. Quarterly Journal of International Agriculture, 44, 37-60.

Barrett, C.B. and Reardon, T. (2000): Asset, activity, and income diversification among African agriculturalists: Some practical issues. Dept. of Agricultural, Resource and Managerial Economics, Cornell University, Ithaca, NY, USA.

Benin, S., Smale, M., Pender, J., Gebremedhin, B. and Ehui, S. (2004): The economic determinants of cereal crop diversity on farms in the Ethiopian highlands. Agricultural Economics, 31 (2-3), 197-208. https://doi.org/10.1016/j.agecon.2004.09.007

Cavatassi, R., Lipper, L. and Winters, P. (2012): Sowing the seeds of social relations: social capital and agricultural di- 
versity in Hararghe Ethiopia. Environment and Development Economics, 17 (5), 547-578. https://doi.org/10.1017/ S1355770X12000356

Chavas, J.-P., Petrie, R. and Roth, M. (2005): Farm Household Production Efficiency: Evidence from The Gambia. American Journal of Agricultural Economics, 87 (1), 160-179. https://doi. org/10.1111/j.0002-9092.2005.00709.x

Coelli, T. and Fleming, E. (2004): Diversification economies and specialisation efficiencies in a mixed food and coffee smallholder farming system in Papua New Guinea. Agricultural Economics, 31 (2-3), 229-239. https://doi.org/10.1016/j. agecon.2004.09.010

Diiro, G.M. and Sam, A.G. (2015): Agricultural technology adoption and Nonfarm earnings in Uganda: a Semiparametric analysis. The Journal of Developing Areas, 49 (2), 145-162.

Duflo, E., Kremer, M. and Robinson, J. (2008): How High Are Rates of Return to Fertilizer? Evidence from Field Experiments in Kenya. American Economic Review, 98 (2), 482-488 https://doi.org/10.1257/aer.98.2.482

Dupree, L. (1973): Afghanistan, Oxford Pakistan paperbacks. Oxford University Press, United Kingdom.

Ellis, F. (1998): Household strategies and rural livelihood diversification. Journal of Development Studies, 35 (1), 1-38. https:// doi.org/10.1080/00220389808422553

Finlay, K. and Magnusson, L.M. (2009): Implementing weakinstrument robust tests for a general class of instrumental-variables models. The Stata Journal, 9 (3), 398-421. https://doi.org/10.1177/1536867X0900900304

Gebregziabher, K., Mathijs, E., Maertens, M., Deckers, J., Bauer, H. and Gebrehiwot, K. (2012): Is Non-Farm Income Relaxing Farm Investment Liquidity Constraints for Marginal Farms? An Instrumental Variable Approach. International Journal of Economics and Finance Studies, 4 (1), 123-132.

Greene, W.H. (2012): Econometric analysis, 7th eds. Prentice Hall, Boston, USA.

Hitayezu, P., Zegeye, E.W. and Ortmann, G.F. (2016): Farm-level crop diversification in the Midlands region of Kwazulu-Natal, South Africa: patterns, microeconomic drivers, and policy implications. Agroecology and Sustainable Food Systems, 40 (6), 553-582. https://doi.org/10.1080/21683565.2016.1156595

Joshi, P.K., Gulati, A. and Cummings, R.W. (2007): Agricultural Diversification in South Asia: Beyond Food Security. New Delhi: Academic Foundation 47-82, India.

Kilic, T., Carletto, C., Miluka, J. and Savastano, S. (2009): Rural nonfarm income and its impact on agriculture: evidence from Albania. Agricultural Economics, 40 (2), 139-160. https://doi. org/10.1111/j.1574-0862.2009.00366.x

Kurosaki, T. (2003): Specialization and Diversification in Agricultural Transformation: The Case of West Punjab, 1903-92. American Journal of Agricultural Economics, 85 (2), 372-386. https://doi.org/10.1111/1467-8276.00126

Maletta, H. and Favre, R. (2003): Agroecological zones. Food and Agriculture Organization of the United Nations, Rome, Italy.

McNamara, K. and Weiss, C. (2005): Farm Household Income and On- and Off-Farm Diversification. Journnal of Agricultural and Applied Economics, 37 (1), 37-48. https://doi.org/10.1017/ S1074070800007082

Mesfin, W., Fufa, B. and Haji, J. (2011): Pattern, trend and determinants of crop diversification: empirical evidence from smallholders in eastern Ethiopia. Journal of Economics and Sustainable Development, 2 (8), 78-89.

Minot, N., Epprecht, M., Anh, T.T.T. and Trung, L.Q. (2006): Income Diversification and Poverty in the Northern Uplands of Vietnam. IFPRI (International Food Policy Research Institute), Washington, DC, USA.

Mishra, A.K., El-Osta, H.S. and Sandretto, C.L. (2004): Factors affecting farm enterprise diversification. Agri- cultural Finance Review, 64 (2), 151-166. https://doi. org/10.1108/00214660480001160

Mishra, A.K. and Goodwin, B.K. (1997): Farm income variability and the supply of off-farm labor. American Journal of Agricultural Economics, 79 (3), 880-887. https://doi. org/10.2307/1244429

Newey, W.K. (1987): Efficient estimation of limited dependent variable models with endogenous explanatory variables. Journal of Econometrics, 36 (3), 231-250. https://doi.org/10.1016/03044076(87)90001-7

Ogundari, K. (2013): Crop diversification and technical efficiency in food crop production: A study of peasant farmers in Nigeria. International Journal of Social Economics, 40 (3), 267-287. https://doi.org/10.1108/03068291311291536

Oushy, H. (2010): Farm Resource Management in AfghanistanTraining Course. United States Agency for International Development (USAID), New Mexico State University (NMSU), Afghanistan Water, Agriculture, and Technology Transfer (AWATT) project. Retrieved from: https://aces.nmsu.edu/pubs/ docs/ (Accessed in December 2019).

Petrin, A. and Train, K. (2010): A control Function Approach to Endogeneity in Consumer Choice Models. Journal of Marketing Research, 47 (1), 3-13.

Pope, R.D. and Prescott, R. (1980): Diversification in Relation to Farm Size and Other Socioeconomic Characteristics. American Journal of Agricultural Economics, 62 (3), 554-559. $10.2307 / 1240214$

Ragasa, C. and Mazunda, J. (2018): The impact of agricultural extension services in the context of a heavily subsidized input system: The case of Malawi. World Development, 105, 25-47. https://doi.org/10.1016/j.worlddev.2017.12.004

Ricker-Gilbert, J., Jayne, T.S. and Chirwa, E. (2011): Subsidies and Crowding Out: A Double-Hurdle Model of Fertilizer Demand in Malawi. American Journal of Agricultural Economics, 93 (1), 26-42. https://doi.org/10.1093/ajae/aaq122

Rahman, S. (2009): Whether crop diversification is a desired strategy for agricultural growth in Bangladesh? Food Policy, 34 (4), 340-349. https://doi.org/10.1016/j.foodpol.2009.02.004

Rao, P.P., Joshi, P.K., Kumar, S. and Ganguley, K. (2008): Agriculture Diversification in Andhra Pradesh, India: Patterns, Determinants and Implications (No. 2). ICRISAT and IFPRI, New Delhi, India.

Reardon, T., Berdegué, J. and Escobar, G. (2001): Rural nonfarm employment and incomes in Latin America: overview and policy implications. World Development, 29 (3), 395-409. https:// doi.org/10.1016/S0305-750X(00)00112-1

Smale, M., Kusunose, Y., Mathenge, M.K. and Alia, D. (2016): Destination or Distraction? Querying the Linkage Between Off-Farm Work and Food Crop Investments in Kenya. Journal of African Economies, 25 (3), 388-417. https://doi.org/10.1093/jae/ejv032

Stampini, M. and Davis, B. (2009): Does nonagricultural labor relax farmers' credit constraints? Evidence from longitudinal data for Vietnam. Agricultural Economics, 40 (2), 177-188. https:// doi.org/10.1111/j.1574-0862.2009.00368.x

Stoeffler, Q. (2016): Crop portfolio choices in Burkina Faso. The Journal of Developing Areas, 50 (3), 261-285. https://doi. org/10.1353/jda.2016.0103

Tadesse, G. and Bahiigwa, G. (2015): Mobile Phones and Farmers' Marketing Decisions in Ethiopia. World Development, 68, 296-307. https://doi.org/10.1016/j.worlddev.2014.12.010

Tavva, S., Aw-Hassan, A., Rizvi, J. and Saharawat, Y.S. (2017): Technical efficiency of wheat farmers and options for minimizing yield gaps in Afghanistan. Outlook on Agriculture, 46 (1), 13-19. https://doi.org/10.1177/0030727016689632

Turner, E.C. (2014): Determinants of crop diversification among Mozambican smallholders: Evidence from household panel data. M.S. Thesis, Michigan State University, USA. 
Van Dusen, M.E. and Taylor, J.E. (2005): Missing markets and crop diversity: evidence from Mexico. Environment and Development Economics, 10 (4), 513-531. https://doi.org/10.1017/ S1355770X05002317

Weinberger, K. and Lumpkin, T.A. (2007): Diversification into Horticulture and Poverty Reduction: A Research Agenda. World Development, 35 (8), 1464-1480. https://doi.org/10.1016/j. worlddev.2007.05.002

Weiss, C.R. and Briglauer, W. (2000): Determinants and dynamics of farm diversification. FE Workingpaper/Universität Kiel, Department of Food Economics and Consumption Studies, Kiel, Germany.
Wooldridge, J.M. (2015): Control function methods in applied econometrics. Journal of Human Resources, 50 (2), 420-445. https://doi.org/10.3368/jhr.50.2.420

World Bank (2014): Agricultural sector review: revitalizing agriculture for economic growth, job creation, and food security. Washington, DC, USA.

Zereyesus, Y.A., Embaye, W.T., Tsiboe, F. and Amanor-Boadu, V. (2017): Implications of Non-Farm Work to Vulnerability to Food Poverty-Recent Evidence from Northern Ghana. World Development, 91，113-124. https://doi.org/10.1016/j.worlddev.2016.10.015

\section{Appendix}

\section{ANNEX I. IVTobit and IVProbit estimations for joint crop diversification decisions}

Table 3: Unconditional Marginal Effects from the IVTobit and IVProbit models.

\begin{tabular}{|c|c|c|c|c|c|c|}
\hline \multirow{2}{*}{ Variable } & \multicolumn{2}{|c|}{ 1st Stage } & \multicolumn{2}{|c|}{ IVTobit } & \multicolumn{2}{|c|}{ IVProbit } \\
\hline & Coefficient & SE & ME & SE & ME & $\mathbf{S E}$ \\
\hline Off-farm Income (in 10K AFN) & - & - & $-0.015 * * *$ & 0.001 & $-0.070^{* * *}$ & 0.009 \\
\hline Total Land (ha) & $-0.062 * *$ & 0.027 & $0.003 * * *$ & 0.001 & $0.052 * * *$ & 0.015 \\
\hline Transport Equip. (1=access) & $0.926^{* * *}$ & 0.251 & $0.031 * * *$ & 0.007 & $0.102 * * *$ & 0.031 \\
\hline Communication Equip ( $1=$ yes) & 0.394 & 0.298 & $0.026 * * *$ & 0.008 & $0.071 * *$ & 0.034 \\
\hline Cattle Ownership (N) & $-0.144 * *$ & 0.060 & $0.004 * *$ & 0.002 & 0.012 & 0.008 \\
\hline Oxen \& Yaks $(\mathrm{N})$ & $-0.685^{* * *}$ & 0.191 & $0.024 * * *$ & 0.005 & $0.099 * * *$ & 0.025 \\
\hline Tractor \& Thresher $(\mathrm{N})$ & 0.522 & 0.503 & $0.051 * * *$ & 0.013 & $0.311 * * *$ & 0.082 \\
\hline Land Quality (1=good) & -0.288 & 0.341 & $0.050 * * *$ & 0.009 & $0.226 * * *$ & 0.042 \\
\hline Landscape (1=open plain $)$ & $0.806^{* * *}$ & 0.268 & $0.064 * * *$ & 0.007 & $0.344 * * *$ & 0.035 \\
\hline Irrigation Water (1=access) & $0.469 * *$ & 0.235 & $0.029 * * *$ & 0.006 & $0.106^{* * *}$ & 0.029 \\
\hline Household Size (persons) & $0.589 * * *$ & 0.035 & $0.014 * * *$ & 0.001 & $0.060 * * *$ & 0.010 \\
\hline Head Edu (1=primary \& sec) & $1.378 * * *$ & 0.351 & $0.041 * * *$ & 0.01 & $0.194 * * *$ & 0.047 \\
\hline Head Edu (2=upper sec) & $3.572 * * *$ & 0.420 & $0.088 * * *$ & 0.013 & $0.435 * * *$ & 0.058 \\
\hline Head Edu ( $3=$ teacher college $)$ & $2.103 * * *$ & 0.737 & $0.042 * *$ & 0.021 & $0.222 * * *$ & 0.083 \\
\hline Head Edu (4=uni \& grad) & $6.757 * * *$ & 0.954 & $0.128 * * *$ & 0.031 & $0.523 * * *$ & 0.145 \\
\hline Head Sex $(1=$ male $)$ & -0.049 & 1.620 & $0.080 * *$ & 0.04 & 0.232 & 0.176 \\
\hline Head Age (years) & 0.002 & 0.008 & 0.0002 & 0.00 & 0.001 & 0.001 \\
\hline Extension Services $(1=$ access $)$ & $-1.123 * * *$ & 0.295 & $-0.017 * *$ & 0.008 & -0.043 & 0.035 \\
\hline Distance to Road $(\mathrm{km})$ & $-0.022 *$ & 0.013 & $-0.005 * * *$ & 0.001 & 0.001 & 0.002 \\
\hline Distance to Market $(1=<1 \mathrm{~h})$ & 0.262 & 0.564 & $0.030 * *$ & 0.015 & 0.069 & 0.057 \\
\hline Distance to Market $(2=>1 \mathrm{~h})$ & -0.448 & 0.553 & 0.016 & 0.015 & 0.051 & 0.055 \\
\hline AEZ $2(\mathrm{CM})$ & -0.922 & 0.769 & $0.041 * *$ & 0.00 & $0.267 * * *$ & 0.087 \\
\hline AEZ 3 (HFL) & 1.011 & 0.929 & -0.023 & 0.023 & -0.069 & 0.147 \\
\hline AEZ 4 (SMF) & 1.273 & 0.787 & $0.130 * * *$ & 0.02 & $0.732 * * *$ & 0.094 \\
\hline AEZ 5 (HVSB) & -0.842 & 0.881 & $-0.049 * *$ & 0.022 & $-0.328 * * *$ & 0.108 \\
\hline AEZ 6 (TP) & -0.562 & 0.869 & $-0.059 * * *$ & 0.021 & -0.162 & 0.101 \\
\hline AEZ 7 (NMF) & -0.804 & 0.775 & $0.065 * * *$ & 0.02 & $0.284 * * *$ & 0.088 \\
\hline AEZ 8 (EMF) & -1.096 & 0.779 & $0.162 * * *$ & 0.02 & $0.604 * * *$ & 0.096 \\
\hline IV1- Share of Off-farm Income in Total Income within District & $10.612 * * *$ & 0.485 & - & - & - & - \\
\hline IV2-Lag District Level OFY & $0.001 * * *$ & 0.000 & - & - & - & - \\
\hline Constant & $-5.833 * * *$ & 1.881 & - & - & - & - \\
\hline Log-Likelihood & \multicolumn{2}{|c|}{$-32,065.16$} & \multicolumn{2}{|c|}{$-35,949.00$} & \multicolumn{2}{|c|}{$-36,900.66$} \\
\hline Wald Test of exogeneity (chi2, p-value) & \multicolumn{2}{|c|}{ - } & $-142.25 * * *$ & 0.000 & $96.22 * * *$ & 0.000 \\
\hline Amemiya-Lee-Newey statistic (chi2, p-value) & \multicolumn{2}{|c|}{ - } & $\begin{array}{ll}- & 0.500\end{array}$ & 0.479 & 0.548 & 0.459 \\
\hline Left censored observations(N) & \multirow{2}{*}{\multicolumn{2}{|c|}{8613}} & \multirow{2}{*}{\multicolumn{2}{|c|}{$\begin{array}{l}2,830 \\
5782\end{array}$}} & & \\
\hline Uncensored observations $(\mathrm{N})$ & \multirow{2}{*}{\multicolumn{2}{|c|}{8,613}} & & & & \\
\hline $\mathrm{N}$ & & & \multicolumn{2}{|c|}{8,613} & \multicolumn{2}{|c|}{8,613} \\
\hline
\end{tabular}

Notes: Marginal Effects for factor levels is the discrete change from the base level significance levels indicated by $* \mathrm{p}<0.10, * * \mathrm{p}<0.05, * * * \mathrm{p}<0.010$

Source: own composition based on ALCS (2013-14) data 